\title{
Help2care: ehealth strategies for self care of users and caregivers based on Nightingale's work
}

\author{
Help2care: estratégias ehealth de autocuidado para usuários e cuidadores baseadas no trabalho de Nightingale \\ Help2care: estrategias eSalud de autocuidado para usuarios y cuidadores basadas en el trabajo de Nightingale
}

Ana Isabel Fernandes Querido' ORCID: 0000-0002-5021-773X

Carlos António Laranjeira'

ORCID: 0000-0003-1080-9535

Maria dos Anjos Coelho Rodrigues Dixe' ORCID: 0000-0001-9035-8548

'Politécnico de Leiria, Escola Superior de Saúde, ciTechCare Center for Innovative Technology and Health Care. Leiria, Portugal.

How to cite this article: Querido AIF, Laranjeira CA, Dixe MACR. Help2care: Ehealth strategies for self care of users and caregivers based on nightingale's work. Rev Bras Enferm. 2020; 73(Suppl 5):e20200358. doi: http://dx.doi.org/10.1590/0034-7167-2020-0358

Corresponding author: Ana Isabel Fernandes Querido E-mail: ana.querido@ipleiria.pt

EDITOR IN CHIEF: Antonio José de Almeida Filho ASSOCIATE EDITOR: Álvaro Sousa

Submission: 06-26-2020

Approval: 08-19-2020

\section{ABSTRACT}

Objective: To report the experience of design and implementation of the Help2Care (an ehealth program that aims to support informal caregivers of dependent people); and to identify its structure and functionality. Methods: This is a Portuguese experience report about Help2Care, a practice-based action research project carried out between 2017 and 2019, having as a guiding axis Florence Nightingale's concepts about the relevance of the home-care environment. Results: The Help2Care program revealed itself to be a valuable support tool for providing better healthcare learning, counselling, and assistance of the informal caregivers of dependent people. Different ehealth strategies were used to empower caregivers in self-care in order to have a safe transition between contexts of care at the time of patient discharge. Conclusion: Help2Care allows to inspire other ways of providing care, as well as a reduction in the readmission rate in health organizations for patients who reveal poor care support in home environments.

Descriptors: Caregivers, Self-Care, Nursing Care, Continuity of Patient Care, ehealth strategies

\section{RESUMO}

Objetivo: Relatar a experiência sobre o desenho e implementação do Help2Care (um programa de eSaúde que visa apoiar os cuidadores informais de pessoas dependentes); e identificar a sua estrutura e funcionalidade. Método: Este é um relato de experiência Portuguesa sobre o Help2Care, um projeto de pesquisa-ação (2017-2019), tendo como eixo orientador os conceitos de Florence Nightingale sobre a relevância do ambiente de atendimento domiciliar. Resultados: O programa Help2Care revelou ser uma valiosa ferramenta de apoio para um melhor aprendizado, aconselhamento e assistência dos cuidadores informais de pessoas dependentes. Diferentes estratégias de eSaúde foram utilizadas para capacitar o cuidador no autocuidado, a fim de ter uma transição segura entre contextos de saúde no momento da alta do paciente. Conclusão: O Help2Care permite inspirar outras formas de prestar cuidados, bem como uma redução na taxa de readmissão nas organizações de saúde para pacientes que revelam insuficiente apoio de cuidados em ambientes domiciliares.

Descritores: Cuidadores; Autocuidado; Cuidados de Enfermagem; Continuidade da Assistência ao Paciente; Estratégias de eSaúde.

\section{RESUMEN}

Objetivo: Relatar la experiencia sobre el dibujo e implementación del Help2Care (un programa de eSalud que objetiva apoyar los cuidadores informales de personas dependientes); $y$ identificar su estructura y funcionalidad. Métodos: Esta es una declaración de experiencia Portuguesa acerca del Help2Care, un proyecto de investigación-acción (2017-2019), con los conceptos de Florence Nightingale sobre la relevancia del ambiente de atención domiciliaria. Resultados: El programa Help2Care demostró ser una valiosa herramienta de apoyo para un mejor aprendizaje, asesoramiento y asistencia a los cuidadores informales de personas dependientes. Se utilizaron diferentes estrategias de eSalud para capacitar a los cuidadores en el autocuidado, para tener una transición segura entre los contextos de salud después del alta del paciente. Conclusión: El Help2Care permite inspirar otras formas de proporcionar atención, así como una reducción en la tasa de reingresos en organizaciones de salud para pacientes que revelan apoyo insuficiente en su casa.

Descriptores: Cuidadores; Autocuidado; Cuidados de Enfermería; Continuidad de la Asistencia al Paciente; Estrategias de eSalud. 


\section{INTRODUCTION}

Population ageing has now become a major concern of increasing importance to developed and developing countries alike. Between 2015 and 2050, worldwide, the number of persons aged 60 and over is expected to more than double, while that of persons aged 80 or over to more than triple. In addition, most of these people have difficulties to perform their activities of daily living (ADL), since they live alone or with other elderly people ${ }^{(1)}$. Furthermore, the increase in the average life expectancy is accompanied by an increase in individuals suffering from postoperative and chronic conditions, neurological disorders, among others, which, in turn, indicate the need for continuous care outside a health organization. Currently, informal caregivers are recognized in the Portuguese National Health Plan, however, public support services for the elderly and for dependent people are insufficient to meet the needs of this population ${ }^{(2)}$.

Between $20 \%$ and $30 \%$ of users with chronic diseases are hospitalized during the first 30 days after hospital discharge ${ }^{(3)}$ due to the absence of a discharge planning, difficulties in managing the therapeutic regimen, lack of knowledge about the diagnosis and medication, lack of post-discharge monitoring, lack of social support, difficulty in managing/assisting the patient by not knowing what to do to manage care in the future and by not including the caregiver in the discharge process, although they wish to be included ${ }^{(4)}$.

Given the increasing number of dependent people, families are increasingly faced with the responsibility of caring for their relatives in various complex or less complex situations for short or long periods of time and for which they are not prepared. Moreover, a growing number of family caregivers are members of the so-called "sandwich generation," balancing care for dependent children and ageing parents simultaneously, adding to the complexity and stress of care responsibilities ${ }^{(5)}$. There are several studies showing that the family members providing care to their relatives need to acquire abilities that enable them to be competent in their performance, and health care professionals have an indispensable role in their training ${ }^{(6)}$. Empowering caregivers can help in reducing health care costs, improve the quality of life of both user and caregiver, their mental health, and provide greater satisfaction with their care. The continued support to caregivers can help them in decision making during less serious health situations and to use fewer health services.

It is crucial to emphasize that informal caregivers are not health professionals; therefore, they need training and/or information to carry out their function correctly. This information is only transmitted to them on the day of discharge of the patient, which is not enough to take due care, thus requiring continuous access to information and support from the health care professionals. Also, a paucity of training activities during the hospital stay has been reported by the caregivers at the time of discharge and confirmed by the nurses. In addition, the enormous amount of information available in the internet frequently creates confusion about its use, and the low literacy of the majority of the caregivers may interfere in the choice of the best reliable information needed to care for the dependent person.

In Portugal, the high percentage of hospital readmissions poses a national health challenge. Beyond the economic impact, this reality also influences, at various levels, the dependent person and his/her caregivers. Nowadays, with the advances in technologies, nurses are challenged to use Information and Communication Technology (ICT) in care planning and to develop interventions using ICT resources tailored to the clients' needs (both patients and families). The quality of care provided by an informal caregiver depends on the quality of life and well-being of the caregivers themselves. Moreover, and although literature refers to difficulties in caregiving, it is also acknowledged that, even when facing similar situations, caregivers may experience different levels of burden and/or different levels of subjective well-being ${ }^{(7)}$.

As caregivers represent an essential and indispensable part of the provision, organization and sustainability of health and social care systems. "It is thus of utmost importance to understand the resources these caregivers use (or will need) to minimise the physical and emotional burden they may face, which could be linked to the care provided. Health professionals may use this information to provide better care plans, enhancing supportive measures and, thus, leading to more successful care conditions" (p.2) $)^{(7)}$.

\section{OBJECTIVE}

To present an experience report about the process of development of the Help2Care digital program for supporting informal (family) caregivers of dependent people, in their caregiving role; and to identify the structure and functionality of Help2Care in providing self-management support to caregivers.

\section{METHODS}

This is an experience report about the development of Help2Care - an ICT resource to support and monitor the training of caregivers of dependent people, across the different settings of care (e.g. in transitions of care contexts, namely after hospital discharges).

The Help2Care project design is part of a larger study entitled "Help2Care - Help to care for users and caregivers". The main goal of this interdisciplinary action-based research project, involving students, professors, and stakeholders, is to develop a training model of caregivers and users for self-care and train health professionals for its use. It was carried out from October 2017 to September 2019 and driven by practical results based on a learn-by-action, practice, experience and intervention. The research problem was originally raised by one Portuguese hospital partner of the research consortium, which sought an academic/ expert collaboration in facing the problem of readmissions and high recurrence to emergency departments of dependent users and their carers in areas such as hygiene and comfort, mobility and balance (falls, pressure ulcers), obstruction of feeding probes, malnutrition and dehydration, communication, management of symptoms and medication, and technics related with the prevention of the caregivers exhaustion.

The research team was composed by ten professionals with backgrounds in Nursing, Speech Therapy, Physiotherapy, Occupational Therapy, Nutrition and Dietetics, and Informatics.

The project was submitted and approved by an Ethical Committee (nr.04 - 2017/05/02) and reported and authorized by the National Committee of data protection (nr. 3289/2017). 


\section{Theoretical framework for management of chronic illness} in home care

The Environmental Theory, by Florence Nightingale, defined nursing as the act of utilizing the environment of the patient to assist him/her in his/her recovery. It involves the nurses'initiative to configure environmental settings appropriate for the gradual restoration of the patient's health, and states that external factors associated with the patient's surroundings affect life or biologic and physiologic processes, and their development. Nightingale discussed the Environmental Theory in her book Notes on "Nursing: What it is, and What it is Not". She is considered to be the first theorist in nursing and paved the way for the foundation of the nursing profession as we know it today.

Nightingale's work was written for caregivers at home, with methods and guidelines to improve the health of patients, aiming to support the work of these professionals. She directed her teachings to women, because they were primarily responsible for family $\operatorname{care}^{(8)}$. The main scenario addressed by Nightingale in her theory was the home environment. She taught how to create environments that were favorable to the recovery of the patient's health at their home ${ }^{(8)}$. She also described healing as the creating of healing environments that address not only the problem/concern, but all aspects of a person's health, from their social needs to mind-body-spirit and environmental needs (internal and external). It is about looking at the big picture and how it relates to overall health and wellness.

\section{RESULTS}

For greater clarity of the results, we begin by presenting the structure of the digital platform that supports the Help2care program, followed by a description of the steps and activities developed for its implementation.

\section{Structure of the digital platform}

The digital platform development architecture includes three interrelated resources/modules:

a) A mobile application (app) for the caregiver and/or user, with information about their care needs and respective procedures appropriate to address those needs (e.g., information on how to keep a unobstructed clear tube, in the form of texts, videos, FAQs, quizzes, appropriate procedures and emergency contact). The type and format of the information to be provided for each type of need was discussed among researchers from different health care perspectives as well as professionals from design and computer science. Several different materials to support caregivers' education and training were produced in order to be selected and available according to their needs and literacy. The app also facilitates the direct contact between the caregivers and their health care case manager, so they can update their needs and doubts regarding their caregiving role.

b) A back-office web application for health professionals where they can manage caregivers and related dependent persons. This also allowed for the connection between the hospital and primary health care professionals through the information sharing of users and caregivers. The discharge planning can be started by the nurse at the hospital using this back-office web platform, where the community nurse can also be included and participate in the caregiver education process towards an optimal patient home discharge. From the back-office, a health professional can evaluate the needs and abilities of the caregiver through the tools developed in the first activity of the project, and therefore tailor the materials that best respond to train and prepare the caregiver and patient for the best transition between the hospital and home. The back-office also allowed monitoring the use of the mobile application through general and specific metrics. A dashboard allows healthcare professionals to access data from metrics using the mobile application for each caregiver, as well as the general indicator data (statistical), correlating metrics using the mobile application of all caregivers registered on the platform versus the caregivers in charge.

c) Caregiver's portal - web application, where general caregiver information can be consulted [http://www.help2care.pt/]. This information includes: Knowledge about clients and caregivers concerning self-care abilities in hygiene and comfort, mobility and balance, obstruction of food probes, malnutrition and dehydration, communication, management of symptoms, management of medication and techniques related with the prevention of caregiver exhaustion; caregiver capacitation documentation, including tutorials, videos, quizzes, written texts, FAQs on how to perform certain care procedures; user manuals of the caregiver mobile app, and instructions on how to download and install it (minimum system requirements, compatibility). Information about community resources (for instance, nearby associations that provide certain home healthcare services and training).

\section{Experience in the Help2Care ehealth application}

The implementation of the ehealth application starts with the selection of the dyad formed by the dependent person and the family caregiver in a hospital environment, carried out by the nurse. This selection is based on the identified health needs, so that the digital tool and its materials can be tailored to the dyad's self-care needs, thereby favouring a healthy transition to their natural environment.

The care of individuals with chronic diseases can impose a heavy physical and emotional burden on informal caregivers because they must combine their own family duties with those of caregiving, quite often resulting in withdrawal from their professional, family, and social lives. Changes that occur during treatment and the progression of disease itself often cause a significant discomfort to the informal caregivers. The recognition of variables able to affect the quality of life of informal caregivers can guide the selection of the most adequate interventions aiming to improve care as a whole. Therefore, accurate identification of the degree to which caregiving interferes with the wellbeing of informal caregivers is highly relevant.

In order to frame the program, the 4 concepts of Florence Nightingale's theory were used, namely: a) Nursing which allows to configure environmental settings appropriate for the gradual restoration of the patient's health; b) Human Beings are defined in relation to their environment and to the impact of 
the environment upon them. In this context we used the dyad dependent person and family caregiver, who are simultaneous targets and care partners; c) Environment, in which all that surrounds human beings is considered in relation to their state of health, specially the home context; and d) Health, observed as a purpose of the nurse's intervention. As Nightingale did not define health specifically, we used a health concept that aims at the well-being and satisfaction of self-care needs.

This project brings new evidence to the progress of the knowledge and technology that promote the creation of Help2Care - an ehealth innovative program tailored to target populations - caregivers, dependent users and their health case managers - , providing self-care management support to caregivers in caring for their dependent relatives. The project activities were planned and developed in a cycle of six steps and care activities which composed the Help2Care ehealth intervention program (Figure 1).

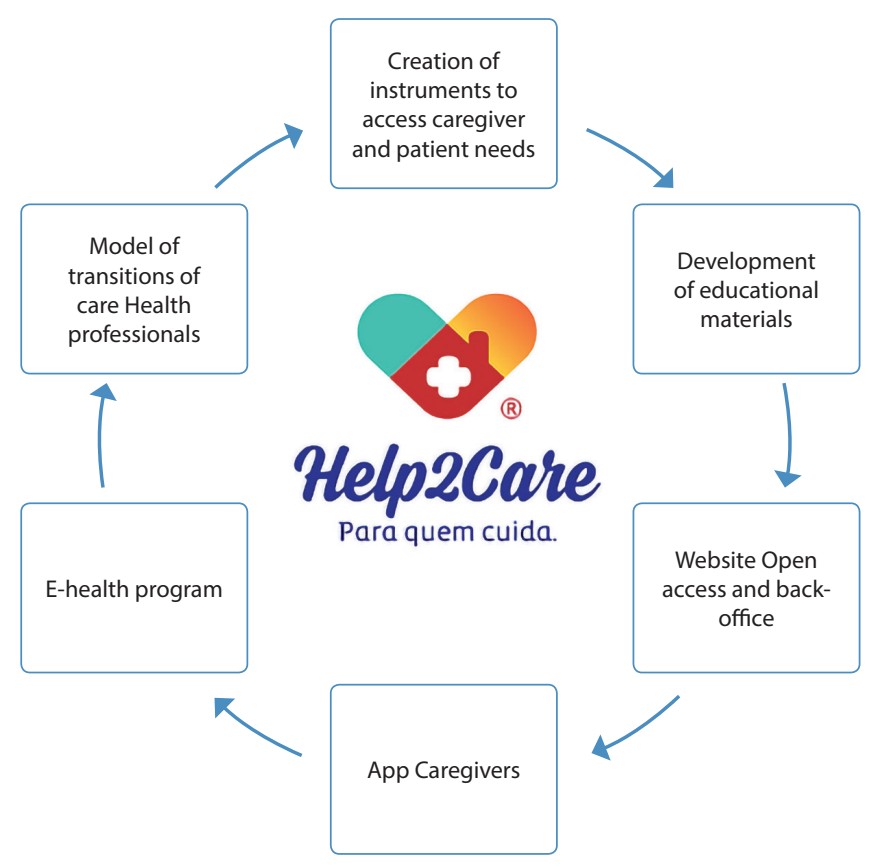

Figure 1 - Help2Care steps and activities

Through action-based research grounded on practice, this project enabled an innovative thinking process by all participants, including managers, clinical and administrative staff, users, and their caregivers. The use of technologies such as the smartphone and the Internet is associated with a more rational use of health services and will optimize communication within the health care system and straight communication between health providers and service users ${ }^{(6)}$. Also, outputs produced by Help2Care respond to quality monitoring of health care provision in the transition of care from hospitals to community care.

Help2care addresses the impact of diseases and disability in health self-care of dependent users and their caregivers (step 1). Most of the dependent users have one or more chronic diseases, and therefore, needs and capabilities of users and caregivers are best characterized by symptoms, self-care behaviours and functional limitations that are monitored using specific instruments. The instruments developed in this project resulted from the scientific literature state of the art, meetings with informal caregivers and health care professionals, and the inclusion of items from other instruments. The instruments developed in this project are relevant and valid indicators to access needs and abilities of caregivers and users and monitoring chronic conditions ${ }^{(7)}$.

Following the caregiver and dependent person needs, the production of educational materials occurred in a project stage involving students, professors and health care professionals (step 2). Based on the previous evidence, written materials (books and e-books), as well as illustrations, were produced. Professors, nurses, physiotherapists and skilled caregivers were involved in film productions. Ten films were produced on several technical procedures by caregivers at home, available on-line. A website was created (step 3 ) integrating a public component where all the education materials are freely available, and a back-office to be managed by health care professionals and project administrator. An app was created both in Android and IOS format to be used by caregivers (step 4). The educational materials tailored to each caregiver can be accessed by them from the app. The app contents are, therefore, managed by the health care professionals. The app is also prepared to serve as a direct communication support between the health care professional and the caregivers. An ehealth education program of caregivers integrating the ICT and ehealth was developed, in which caregivers' empowerment is used as educational model (step 5). The project is also related to the improvement of the support concerning the transition process from hospital to home and its monitoring and management. For that, a model of transitions was discussed and designed based on the ehealth program and using the ICT/ehealth tools along the process of transition of care (step 6).

Help2Care enhance professionals' competencies on client and caregiver's empowerment. This project invested in education, training of caregivers, and professional training for ability acquisition, promoting lifelong learning. The majority of activities identified in Help2Care require effective collaboration and/or participation of the organizations benefiting from innovation (hospitals, community health care, other entities supporting caregivers). Through action-based research grounded on practice, this project enabled an innovative thinking process by all participants, including managers, clinical and administrative staff, users and their caregivers. The involvement of organizations and stakeholders in the research process, right from the problem definition phase, contributes to the creation of innovative societies in which all stakeholders gain. From the perspective of Higher Education Institutes, the research team benefits from specific knowledge of who works daily in these organizations; additionally, students are allowed to be part of a real-world context, learning by experience. From the perspective of stakeholders, on one hand, they benefit in a direct manner from formal research outputs' transfer: model for education of caregivers, manual and digital platforms. On the other hand, they also gained from informal knowledge transfer — their collaborative participation in the process ensures a higher commitment regarding the proposed solutions and gives them the opportunity to acquire research and development skills. Also users and caregivers benefit from an education model supported by ICT tools that allowed an innovative way for patients and caregivers 
to be engaged in monitoring and managing chronic conditions, while ensuring a better understanding of their specific problems and needs, leading to more successful innovation.

The main expected outcome of this project is a training model of self-care for caregivers and users, composed by health professionals and caregivers. Manual support (paper, audio description and digital format) and digital and manual platforms made it possible to replicate the empowerment model used by health professionals, which concerned the preparation of the client and/or of the caregiver for the health care transition from the hospital or from the primary healthcare services to their home.

The design and development of the Help2care program had a multidisciplinary and multiprofessional nature, which allowed the construction of various support and training materials. It should be noted that all materials were subjected to facial and content validation by 25 caregivers, which ensured the clarity of the speech and the accessibility of the audio-visual and audiodescriptive materials. Also, this strategy allowed the creation of materials adapted to specific contexts.

So far, usability tests have been performed to the Help2Care, specifically to its mobile and web applications. The mobile app was tested by 20 informal caregivers, while 16 Registered Nurses (RN) tested the web application. The results obtained for the usability tests of the mobile app revealed that caregivers had difficulties regarding some interactive elements in the user interface, and age/experience with smartphones and mobile apps was of great influence in the results. Concerning the web application, RNs reported some difficulty in the navigation flow of the application, causing a loss of context in the accomplishment of tasks (mainly in registering data from caregivers and patients, associating needs to patients and associating training materials to caregivers) ${ }^{(9)}$.

As a result of these preliminary results, the program is expected to be implemented in a large sample, with the aim of evaluating its effectiveness.

\section{Study limitations}

Despite the theory proposed by Florence Nightingale being widely applied in the contexts of teaching, research and care, its exclusive use limited the approach to other theories. In Nightingale's Environmental Theory, there is scant information on the psychosocial environment when compared to the physical environment. Another limitation is concerning its replication, because the cultural context involved and the topic proposed are specific conditions and could show different results when applied by others in different cultural settings.

Lastly, there was variability in success across urban and rural settings, suggesting greater benefits in health outcomes among urban populations when compared to rural ones, which is an important limitation of the Help2Care ehealth tool. Although it is not entirely clear why this variation exists, one explanation could be that urban populations may have greater access to and utilization of technological tools and to the internet. This suggests that careful attention must be given to the availability and distribution of the internet, and to the reasons that lead populations served by health workers to use it, to guarantee that the use of mobile devices, particularly for communication between health workers and informal caregivers, is appropriate.

\section{Contributions for nursing, health or public policy areas}

This project contributes to addressing societal challenges of the $\mathrm{H} 2020$, aligning with 2 societal challenges, namely: a) Health, demographic change and well-being in their general systems of health and the provision of high-quality, economically sustainable and innovative care; prevention, treatment, monitoring and management of disease and disability, lifelong health, active, independent and healthy ageing promoting general health and well-being of informal caregivers, and using tools and inclusive resources, regardless of age and caregiver limitations, for users with diseases and/or disabilities; b) Europe, in a world of change - inclusive societies, and innovative thinkers in the line of action of inclusive societies. In this context, digitally and health literate citizens can play a more active role in their health self-management, resulting in better health outcomes.

Yet, the connections between care and empowerment are not merely economic; care has a substantial social dimension. Carerelated debates and policies must address the rights, autonomy and well-being of both formal and informal caregivers, as well as those of care receivers. Particularly with regard to the latter. The Sustainable Development Goal 3 aims to ensure healthy lives and promote well-being for all, at all ages ${ }^{(10)}$.

The value of the project is rooted on a combination of materials and resources to support self-care, whose development is tailored to caregivers, patients (users) and healthcare professionals in order to improve quality of life and autonomy of dependent users and their caregivers and, simultaneously, bring economic gains. Another asset of this project is the optimization of human and material resources, leading to better and faster communication processes between health care professionals and caregivers, preventing hospital readmissions and avoiding complications resulting from inadequate preparation for discharge. Using practice-based research, nursing students, professors, caregivers and stakeholders will work on the creation and development of solutions in co-construction. The model of education for self-care and its materials are developed in a multidisciplinary team during the project with inputs from the local actors and the target population. The acceptance was tested locally, in close relation to stakeholders, adapting the corrections needed in each step, before moving to the next one, and using a consistent methodology of action-learning research process, learning from shortcomings and failures and incorporating these inputs in the research process.

\section{FINAL CONSIDERATIONS}

The Environmental Theory of Nursing intended by Nightingale is a patient-care theory. It focuses on the alteration of the patient's environment in order to affect change in his or her health. In this way, the model must be adapted to fit the needs of individual patients. The environmental factors affect different patients in ways that are unique to their situations and illnesses, and caregivers must address these factors on a case-by-case basis in order to make sure the factors are altered in a way that best 
cares for an individual patient and his or her needs ${ }^{(8)}$. In recent years, because of the continuous development of the internet, web-based intervention measures have gradually been applied by scholars, with ehealth interventions providing a more convenient and efficient support and education method for home care providers, as they allow caregivers to learn anytime, anywhere ${ }^{(6)}$. Nurses can assist to move ehealth into mainstream health care by understanding its potential to change the landscape of health intervention delivery, integrating ehealth into caregivers' daily care strategies, and supporting the science of ehealth's effectiveness.
We have presented in this paper a digital platform comprised of a web application (back-office) and a mobile application that aims to provide all the training materials that caregivers need to learn to treat their patients, focusing on what the caregivers need to learn in the moment. As such, this platform can have a huge impact on people's lives as well as on healthcare institutions, since, by effectively transmitting information through smartphones, caregivers can improve the way they perform the task of caring for their patients. As a result, healthcare institutions will be less burdened with patient readmissions due to problems in their self-care.

\section{REFERENCES}

1. United Nations. World Population Aging [Internet]. 2015 [cited 2020 Apr 15]. Available from: https://www.un.org/en/development/desa/ population/publications/pdf/ageing/WPA2015_Report.pdf

2. Administração Central do Sistema de Saúde. Monitorização da Rede Nacional de Cuidados Continuados Integrados (RNCCI) 2015 [Internet]. 2016 [cited 2020 Apr 15]. Available from: http://www.acss.min-saude.pt/category/cuidados-de-saude/continuados/

3. Felix HC, Seaberg B, Bursac Z, Thostenson J, Stewart MK. Why do patients keep coming back? Results of a readmitted patient survey. Soc Work Health Care. 2015;54:1-15. doi: 10.1080/00981389.2014.966881

4. Lund L, Ross L, Petersen MA, Groenvold M. The interaction between informal cancer caregivers and health care professionals: a survey of caregivers' experiences of problems and unmet needs. Support Care Cancer. 2015;23:1719-33. doi: 10.1007/s00520-014-2529-0

5. Boyczuk AM, Fletcher PC. The Ebbs and Flows: stresses of sandwich generation caregivers. J Adult Dev. 2015;6;23(1):51-61. doi: 10.1007/ s10804-015-9221-6

6. Sin J, Henderson C, Spain D, Cornelius V, Chen T, Gillard S. eHealth interventions for family carers of people with long term illness: a promising approach? Clin Psychol Rev. 2018;60:109-25. doi: 10.1016/j.cpr.2018.01.008

7. Dixe MA, Teixeira LF, Areosa TJ, Frontini RC, Peralta T, Querido Al. Needs and skills of informal caregivers to care for a dependent person: a cross-sectional study. BMC Geriatr. 2019;19:255. doi: 10.1186/s12877-019-1274-0

8. International Council of Nurses (ICN). International Alliance of Patient's Organizations (IAPO). Notas sobre enfermagem: um guia para cuidadores na atualidade [Internet]. 2010 [cited 2020 Apr 15]. Available from: http://www.here.abennacional.org.br/here/vol4num2resenha.pdf

9. Caroço J, Gomes, N, Martinho R, et al. Challenges on the usability of digital platforms for informal caregivers and health professionals: the case study of Help2Care. Procedia Comput Sci. 2019;164:724-731. doi: 10.1016/j.procs.2019.12.241

10. United Nations Research Institute for Social Development, Policy Innovations for Transformative Change: Implementing the 2030 Agenda for Sustainable Development [Internet]. 2016 [cited 2020 Apr 15]. Available from: http://www.unrisd.org/80256B42004CCC77/(httplnfoFiles) /2D9B6E61A43A7E87C125804F003285F5/\$̧file/Flagship2016_FullReport.pdf 